\title{
АУТОАНТИТЕЛА И ЦИТОКИНОВЫЙ ПРОФИЛЬ У ПАЦИЕНТОВ С БОЛЕЗНЬЮ ГРЕЙВСА И ЭНДОКРИННОЙ ОФТАЛЬМОПАТИЕЙ
}

Свириденко Н.Ю., Бессмертная Е.Г., Беловалова И.М., Михеенков А.А., Шеремета М.С., Никанкина Л.В., Малышева Н.М.

\author{
ФГБУ «НМИЦ эндокринологии» Минздрава России, Москва
}

По современным представлениям, эндокринная офтальмопатия (ЭОП) - это аутоиммунное заболевание, тесно связанное с аутоиммунной патологией щитовидной железы (ЩЖ). Ключевую роль в иммунопатогенезе аутоиммунных заболеваний ЩЖ, в том числе и ЭОП, играют цитокинопосредованные механизмы. Исследование цитокинового профиля, а также антител к тканевым антигенам имеет принципиальное значение для объяснения патогенеза ЭОП и будущих терапевтических стратегий.

ЦЕЛЬ: исследование уровня цитокинов, аутоантител, иммуноглобулинов IgG и IgG4 как медиаторов аутоиммунного воспаления у пациентов с ЭОП и болезнью Грейвса (БГ).

МАТЕРИАЛЫ И МЕТОДЫ: в исследование были включены 52 пациента (104 орбиты) в активной фазе ЭОП и БГ, верифицированные по международным стандартам диагностики, не получавшие ранее лечения по поводу ЭОП. В контрольную группу были включены 14 человек (28 орбит) не имеющих аутоиммунной патологии. Определены концентрации иммуноглобулинов (IgG, IgG4), цитокинов (TNFa, IL-1a, IL-1 $\beta$, IL-2, IL-4, IL-6, IL-8, IL-10, IL-17A, IL-13, TGF- $\beta 1$, TGF- $\beta 3$ ), растворимых рецепторов (sTNFa-RI и TNFa-R2, sIL-6R, IL-2R, антител к рецептору тиреотропного гормона (рTTГ), свободных фракций тироксина (T4) и трийодтиронина (Т3) - свТ4, свТ3, ТТГ в сыворотке крови. Выполнено ультразвуковое исследование (УЗИ) ЩЖ, мультиспиральная компьютерная томография (МСКТ)/магнитно-резонансная томография (МРТ) орбит.

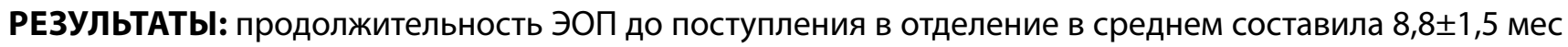
и варьировала от 1 до 48 мес. По степени компенсации тиреотоксикоза находились в состоянии эутире-

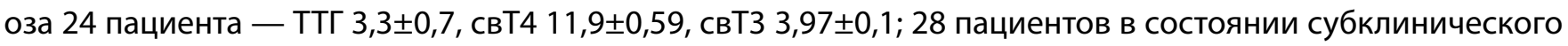

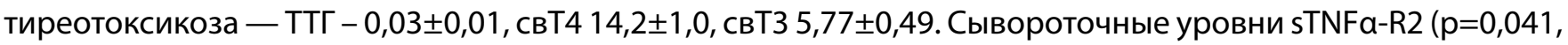
p s0,05), sIL-2R ( $p=0,020, p \leq 0,05)$, TGF $\beta 1$ ( $p=0,000, p \leq 0,001)$ были значимо выше у лиц с ЭОП по сравнению с контрольной группой. С увеличением длительности течения ЭОП повышались концентрации sTNFRa2 $(p=0,038, p \leq 0,05)$ и TGF $\beta 1(p=0,011, p \leq 0,05)$. С увеличением тяжести - концентрация sIL-6R ( $p=0,034$, $\mathrm{p} \leq 0,05)$. С увеличением активности - sTNFa-R 1 ( $p=0,012, p \leq 0,05)$. Выявлено повышенное содержание lgG4 в lgG (более 5\%) у 54\% пациентов.

Выводы: высокие уровни солюбилизированных рецепторов цитокинов: sTNFa-R2, sIL-2R и цитокина TGF $\beta 1$ у пациентов с длительно существующей нелеченой ЭОП и БГ в состоянии эутиреоза и субклинического тиреотоксикоза свидетельствуют об активации регуляторного звена иммунной системы, направленной на супрессию аутоиммунного процесса. Высокое содержание IgG4 в IgG и цитокина TGF $\beta 1$ может определять развитие фиброзных изменений в орбите. Снижение концентрации цитокина TGF $\beta 1$ может свидетельствовать о неблагоприятном течении ЭОП. 